\title{
Using subdural strip electrodes to define functional sensory nerves and the most inferior functional portion of the conus medullaris during detethering surgeries for tethered cord syndrome: a pilot study
}

\author{
Chen-Ya Yang, MD, ${ }^{1}$ Muh-Lii Liang, MD, PhD, ${ }^{2}$ Hsin-Hung Chen, MD, ${ }^{2}$ Jan-Wei Chiu, MD, ${ }^{1}$ \\ Kwong-Kum Liao, MD, ${ }^{3}$ and Tsui-Fen Yang, MD ${ }^{1,4}$

\begin{abstract}
1Department of Physical Medicine and Rehabilitation, Taipei Veterans General Hospital; Departments of ${ }^{2}$ Neurosurgery and ${ }^{3}$ Neurology, The Neurological Institute, Taipei Veterans General Hospital; and ${ }^{4}$ Departments of Physical Therapy and Assistive Technology, National Yang Ming University, Taipei, Taiwan
\end{abstract}

\begin{abstract}
OBJECTIVE The aim of this study was to investigate the feasibility of using subdural strip electrodes, placed just rostral to the surgical field, to record sensory evoked potentials (SEPs) from the lumbosacral sensory nerves and define the most inferior functional portion of the conus medullaris during detethering surgery for spinal dysraphism and/or tethered cord syndrome (TCS).

METHODS Six patients, 2 boys and 4 girls, aged 0.5 to 16 years, were enrolled in this study. One patient had lipomyelomeningocele-related, 4 had myelomeningocele-related, and 1 had diastematomyelia and lipomyelomeningocele-related TCS. In addition to the routine preparations that are needed for performing functional mapping and monitoring during surgery for spinal dysraphism and TCS, the patients had a $1 \times 4$ strip of electrodes placed rostral to the surgical field, where it was secured by a surgeon after opening the dura. With the patient under total intravenous anesthesia, the sensory nerves and conus medullaris were stimulated with a concentric bipolar electrode over the surgical field while SEPs were recorded with the strip electrodes to identify any possible sensory roots with remaining function and the most inferior functional portion of the conus medullaris.
\end{abstract}

RESULTS The SEP amplitudes that were recorded with the subdural strip electrodes ranged from 4 to $400 \mu \mathrm{V}$, and the responses to sensory nerve stimulation were frequently much larger than were those to conus stimulation. Use of the SEP recordings for sensory mapping along with the routine mapping and monitoring techniques allowed detethering to be completed such that none of the patients sustained any new functional deficit after surgery.

CONCLUSIONS Recording SEPs from the functional sensory nerves and conus medullaris through subdural strip electrodes proved to be a feasible and valuable tool during detethering surgery in young patients. This approach may help surgeons achieve maximal detethering while preserving important sensory functions, consequently retaining the patient's quality of life.

https://thejns.org/doi/abs/10.3171/2018.2.SPINE171240

KEYWORDS sensory evoked potentials; intraoperative monitoring; spinal dysraphism; tethered cord syndrome; congenital

$\mathrm{T}$ ETHERED cord syndrome (TCS) can be congenital or develop over time as a sequela of congenital spinal dysraphism. This condition, in which the caudal end of the spinal cord is fixed to bony or inelastic tissue at the base of the spinal canal, mainly affects young children. ${ }^{3,7}$ Myelomeningocele (MMC), lipomyelomeningo- cele (LMC), terminal lipoma, thickened filum terminale, and split cord malformation are the most common causes of TCS. ${ }^{6}$ Often, patients with TCS develop marked neurological deficits, including motor paralysis with resultant musculoskeletal deformities, sensory loss, and bowel and bladder dysfunction. ${ }^{1,5}$ Regarding treatment, surgical inter-

ABBREVIATIONS CMAP = compound muscle action potential; $\mathrm{LMC}=$ lipomyelomeningocele; $\mathrm{MMC}=$ myelomeningocele; $\mathrm{NIOM}=$ neurophysiological intraoperative monitoring; SEP = sensory evoked potential; TCS = tethered cord syndrome.

SUBMITTED November 13, 2017. ACCEPTED February 14, 2018.

INCLUDE WHEN CITING Published online July 13, 2018; DOI: 10.3171/2018.2.SPINE171240. 


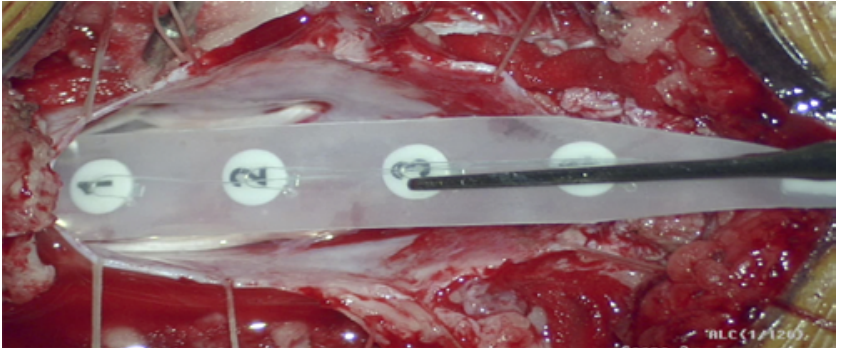

FIG. 1. Photograph showing the placement of a $1 \times 4$ electrode strip in the subdural space immediately rostral to the surgical field. Figure is available in color online only.

vention to detether the cord should be considered early, because it can prevent the progressive neurological deterioration and potentially even reverse any preexisting neurological deficits.13,16 Moreover, delayed correction can lead to irreversible loss of function, as the symptoms will naturally worsen over time. ${ }^{12}$ However, detethering involves meticulous dissection of the lumbosacral nerve roots from the surrounding inelastic structures, which imposes the risk of further neurological deficits.

Neurophysiological intraoperative monitoring (NIOM) has been used since the 1980 s to guide surgical dissection and to safeguard the integrity of neural function. ${ }^{14}$ Conventionally, clinicians have focused mainly on preserving motor function during detethering surgeries by monitoring the presence of electrically triggered compound muscle action potentials (CMAPs). ${ }^{4}$ However, the sensory functions of the S2-4 nerves and conus medullaris are also critical owing to their role in bowel, bladder, and sexual functions. Thus, techniques that can monitor the functions of these essential sensory structures during detethering are needed.

Herein, we introduce a novel NIOM approach for defining functional sensory nerves and the most inferior functional portion of the conus medullaris during detethering surgery for TCS. Using this method, surgeons were able to maximize the extent of detethering and preserve the functional neurological structure of the patients.

\section{Methods}

Six patients, with ages ranging from 6 months to 16 years, underwent detethering surgery due to TCS at Taipei Veterans General Hospital from February 2017 to September 2017. Indications for detethering surgery included functional deterioration in terms of motor, sensory, bowel, and bladder function; progressive musculoskeletal deformity; or back pain. Thorough preoperative evaluations, including physical and neurological examinations and imaging, urodynamic, and electromyography studies, were performed in all cases. The institutional review board of Taipei Veterans General Hospital approved this study.

Routine preparations for intraoperative functional mapping and monitoring, which included recording motor evoked potentials from the muscles in both lower limbs, recording somatosensory evoked potentials from the bilateral tibial nerves, monitoring for the bulbocavernosus reflex, and triggered electromyography for motor mapping,

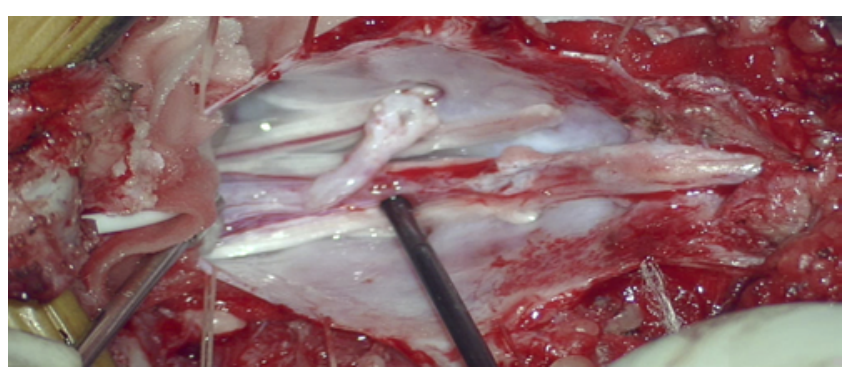

FIG. 2. Photograph showing the concentric bipolar electrode that was used to identify functional sensory nerves and the most inferior functional portion of the conus medullaris at the placode. Figure is available in color online only.

were performed after anesthesia induction..$^{14}$ Total intravenous anesthesia was used during the surgical procedures, and only 1 dose of muscle relaxant was administered during induction. After opening the dura, a $1 \times 4$ electrode strip was placed and secured rostral to the surgical field for recording sensory evoked potentials (SEPs) (Fig. 1). The surgeon then used a concentric bipolar electrode to identify any functional sensory nerves and the most inferior functional portion of the conus medullaris at the placode (Fig. 2). We typically started stimulation at $1 \mathrm{~mA}$ (pulse width: $0.2 \mathrm{msec}, 2.66 \mathrm{~Hz}$ ) and increased the stimulation in 1-mA increments until we reached a maximum of $2 \mathrm{~mA}$ for sensory nerve mapping and $6 \mathrm{~mA}$ for conus mapping. These SEPs were used to define the safe margin for detethering, with the placode severed caudally to the most inferior functional portion of the conus medullaris, which would theoretically preserve sensory functions while achieving maximal detethering. Detailed physical and neurological examinations were repeated before discharge and at follow-up at the joint clinic, performed by a neurosurgeon and a physiatrist. Urodynamic studies were repeated 3 months after surgery.

\section{Results}

Six patients, 2 boys and 4 girls, aged 0.5 to 16 years, were enrolled in this study. Their demographic and clinical characteristics are shown in Table 1. Four of the patients had MMC-related TCS, 1 had LMC-related TCS, and 1 had diastematomyelia and LMC-related TCS. Their TCS-related symptoms included deteriorated motor function and/or increased spasticity of the lower limbs, changes in bowel and bladder function with frequent urinary tract infections, and back pain. The patient in Case 2 was a 2-year-old boy with MMC; primary repair involved only skin closure without detethering at a local hospital right after birth. Preoperative MRI at age 2 (when he presented to us) revealed downward conus medullaris to the S2 level, syrinx at the L2-S4 levels, and attachment of the placodes to the dorsal aspect of the dural sac, and his urodynamic study indicated nonrelaxing striated sphincter-findings that all may be indicative of TCS. The patient in Case 6 was a 6-month-old girl who presented with sacral dimple and scoliosis. Preoperative MRI revealed caudal-type lipoma and diastematomyelia with a low conus medullaris (below the L4 level). These patients both underwent de- 
Yang et al.

TABLE 1. Summary of demographic and clinical characteristics of the participants

\begin{tabular}{|c|c|c|c|c|c|c|}
\hline $\begin{array}{l}\text { Case } \\
\text { No. }\end{array}$ & $\begin{array}{l}\text { Age (in yrs), } \\
\text { Sex }\end{array}$ & $\begin{array}{l}\text { Preop EMG } \\
\text { Findings }\end{array}$ & Diagnosis & Prior Operation & Preop Status & Postop Status \\
\hline 1 & $3, \mathrm{~F}$ & $\begin{array}{l}\text { Bilat L5-S4 } \\
\text { lesions }\end{array}$ & MMC, TCS & $\begin{array}{l}\text { Immediately after birth } \\
\& \text { at age } 2 \text { mos }\end{array}$ & $\begin{array}{l}\text { Unstable gait, bilat foot de- } \\
\text { formities, incontinence }\end{array}$ & No functional deterioration \\
\hline 2 & $2, M$ & Normal & MMC, TCS & $\begin{array}{l}\text { Skin closure w/o de- } \\
\text { tethering after birth }\end{array}$ & Normal & No functional deterioration \\
\hline 3 & $16, M$ & $\begin{array}{c}\text { Bilat S2-4 } \\
\text { lesions }\end{array}$ & MMC, TCS & Immediately after birth & $\begin{array}{l}\text { Recurrent UTI \& hydrone- } \\
\text { phrosis }\end{array}$ & $\begin{array}{l}\text { Improved micturition \& bowel function, } \\
\text { unchanged sexual function }\end{array}$ \\
\hline 4 & $16, \mathrm{~F}$ & $\begin{array}{l}\text { Bilat L5-S2 } \\
\text { lesions }\end{array}$ & LMC, TCS & At age 6 mos & $\begin{array}{l}\text { Back pain, tight heel } \\
\text { cords, recurrent UTI }\end{array}$ & Improved back pain \\
\hline 5 & $6, \mathrm{~F}$ & $\begin{array}{l}\text { Bilat S2-4 } \\
\text { lesions }\end{array}$ & MMC, TCS & Immediately after birth & $\begin{array}{l}\text { Spasticity over both } \\
\text { ankles, incontinence }\end{array}$ & Decreased spasticity \\
\hline 6 & $0.5, \mathrm{~F}$ & Normal & $\begin{array}{l}\text { Diastematomyelia, } \\
\text { LMC, TCS }\end{array}$ & None & Scoliosis & No functional deterioration \\
\hline
\end{tabular}

EMG = electromyography; UTI = urinary tract infection.

tethering surgery due to risk of future neurological deterioration, although no significant functional deficits were present at the time of surgery.

In all patients, the motor evoked potentials of both lower limbs, somatosensory evoked potentials of the bilateral tibial nerves, and bulbocavernosus reflex (if applicable) remained stable throughout the detethering procedures. Additionally, the CMAP response, as triggered with a concentric bipolar stimulator, was used to identify and preserve any functional motor structure. If such a structure showed no CMAP response during motor mapping, then we used sensory mapping to confirm that it was not a functional sensory structure, and thus would be safe to sever if clinically indicated. For sensory mapping, we typically used a 4- to 6-mA stimulus to identify the functional conus medullaris and a 1- to 2-mA stimulus to identify functional sensory nerves, and monitorable responses recorded by the strip could usually be obtained with fewer than 10 averagings (Figs. 3 and 4), which required only $2-3$ seconds using a stimulus frequency of $2.66 \mathrm{~Hz}$. In our series, the SEP amplitudes ranged from 4 to $400 \mu \mathrm{V}$. The responses from both sides of the sensory structures were frequently asymmetrical in amplitude, probably owing to unequal involvement of neural function and/or distortion of the placode due to tethering (Fig. 3), and the responses to sensory nerve stimulation were frequently much larger than the responses to conus stimulation (Fig. 4). Using the SEPs, we were able to define the safe margin for detethering, whereby the placode was severed caudally to the most inferior functional portion of the conus medullaris (Figs. 3 and 5), thus theoretically preserving sensory function while achieving maximal detethering.

One patient had a wound infection requiring hospitalization; there were no other operation-related complications in our 6 cases. The follow-up period ranged from 5 months to 1 year. None of the patients exhibited substantial postoperative functional deterioration or any new neurological deficit at discharge or follow-up at the joint clinic. Urodynamic studies performed 3 months after operation also did not reveal significant interval changes.
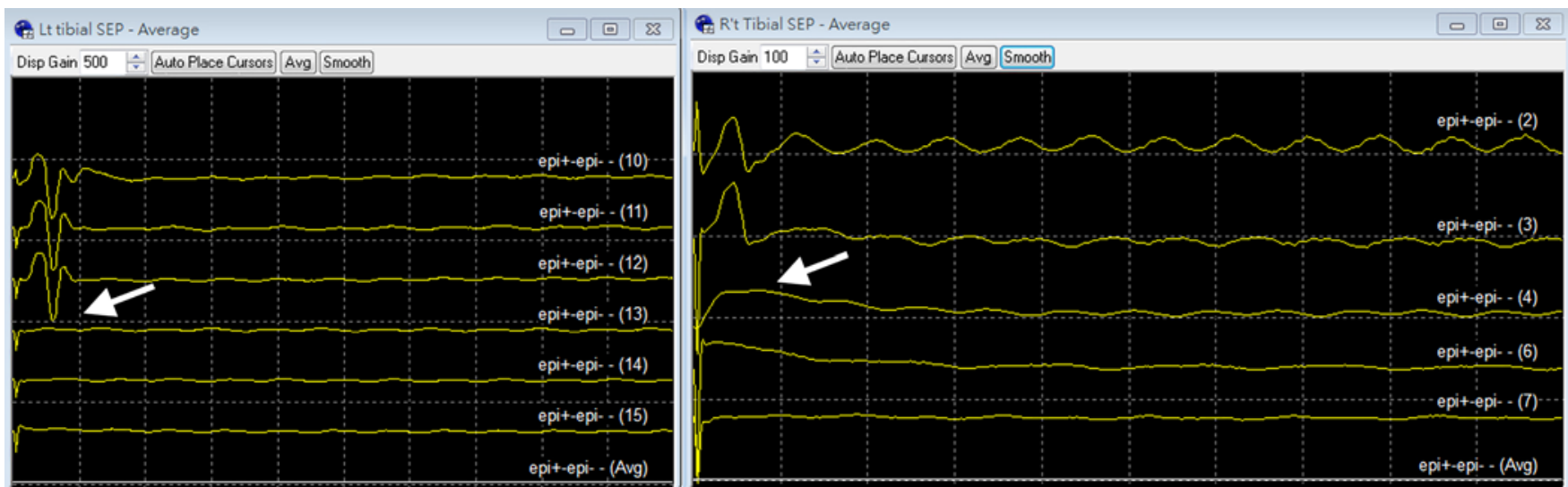

FIG. 3. Sensory-evoked potentials (SEPs) recorded with subdural strip electrodes during stimulation. Stimulation was performed at the left (left panel, amplitude $400 \mu \mathrm{V}$ ) and right (right panel, amplitude $70 \mu \mathrm{V}$ ) placodes in a 3-year-old girl with myelomeningocele and TCS. No SEPs were recordable inferior to the S4 root level on either side (white arrows). Avg = average. Figure is available in color online only. 


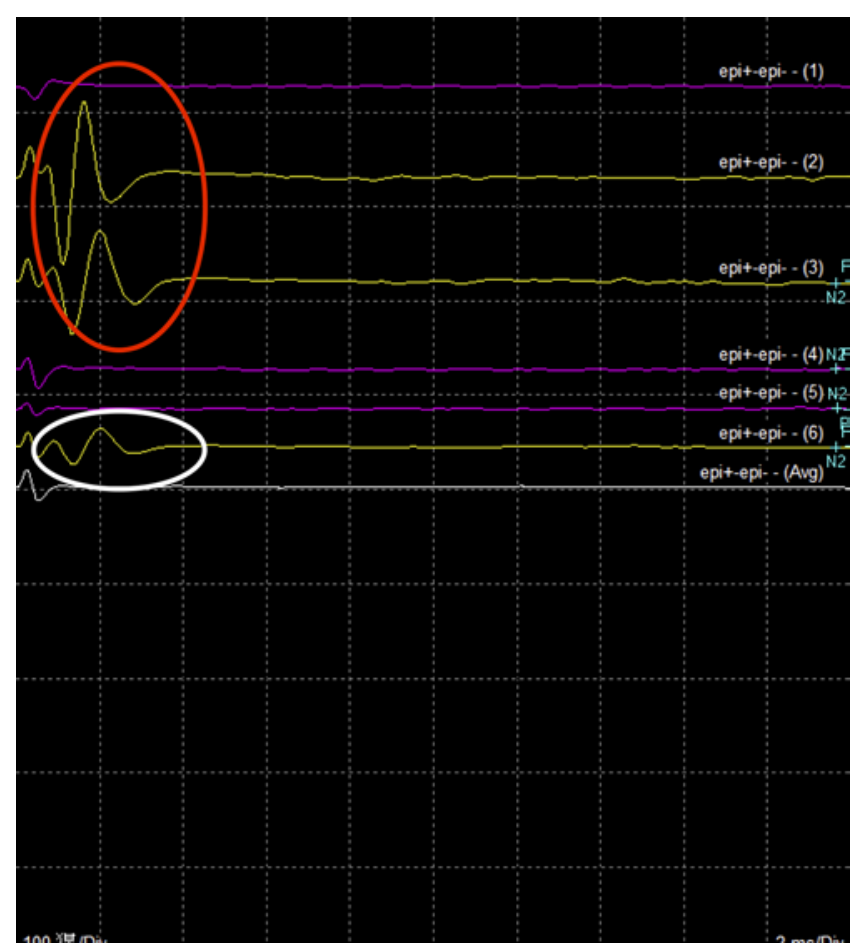

FIG. 4. Sensory-evoked potentials (SEPs) recorded during stimulation. The SEP amplitudes to sensory nerve stimulation (upper 2 traces in red circle, $200 \mu \mathrm{V}$ ) were frequently much larger than were those to conus stimulation (lower trace in white circle, $40 \mu \mathrm{V}$ ). Figure is available in color online only.

One patient reported improvement of back pain and one reported decreased spasticity in both lower limbs. Case 3 involved a 16-year-old boy, who experienced clinically improved micturition and bowel movement after the operation and essentially unchanged sexual function, indicated by continuing to experience erection during sleep as before. All of our patients or their parents were satisfied with the result of the detethering surgery, either regarding relief of present clinical symptoms or ease of anxiety for progressive functional deterioration.

\section{Discussion}

Our study showed that recording subdural SEPs was feasible and useful for mapping sensory nerves and the most inferior functional portion of the conus medullaris and for ensuring that sacral sensory functions remained intact while achieving maximal detethering.

The surgical dissection of lumbosacral nerve roots during detethering may damage neural structures and predispose patients to further functional deterioration after the operation. ${ }^{14}$ Thus, employing NIOM is mandatory for guiding the surgical dissection and for monitoring vital neural functions throughout the procedures to optimize the surgical outcome and minimize postoperative functional deficits. ${ }^{10}$

Although the surveillance of motor function by motor evoked potentials and triggered CMAPs is the primary focus of NIOM during detethering, sensory function is also

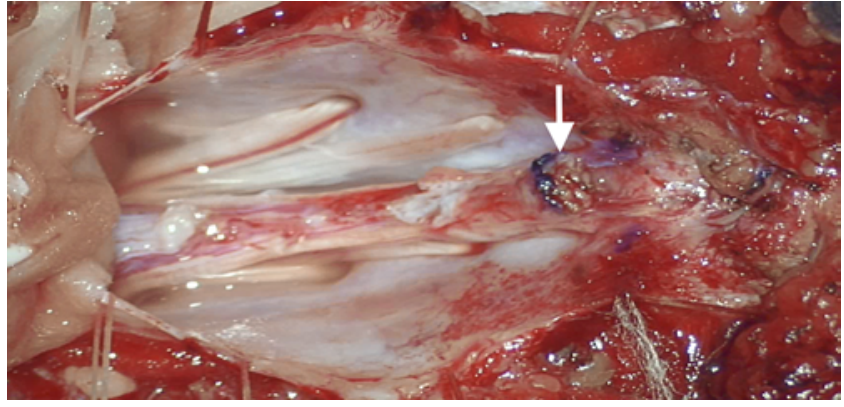

FIG. 5. Using both motor and sensory mapping, the placode was severed caudal to the most inferior functional portion of the conus medullaris (i.e., inferior to the $\mathrm{S} 4$ root level). Figure is available in color online only.

crucial to a patient's quality of life and independence in activities of daily living, and as such, should not be ignored. In 2014, Eccher ${ }^{2}$ suggested that the sensory mapping technique might be useful in detethering surgery because fecal incontinence may occur postoperatively despite mapping of the motor neuronal tissue within ambiguous structures via CMAP recording during the detethering procedure. While several reports and reviews describing various NIOM techniques and methods during detethering surgery have been published previously, ${ }^{7,8,11}$ only one review mentioned the possibility of using the sensory mapping technique, though no data or citations related to this method were presented in that review. ${ }^{9}$ Therefore, to our knowledge, ours is the first report to clearly delineate the procedures for integrating both motor and sensory mapping in the conus medullaris and lumbosacral neural structures during detethering surgery. During detethering of our 4 patients with MMC and TCS, we sometimes could not obtain CMAPs from recording muscles when stimulating the lower portion of the placode but could obtain SEP when shifting to sensory mapping. This definitely altered our surgical decisions, and we would sever the nonfunctional placode at the level determined based on the findings of both motor and sensory mapping instead of the findings provided by motor mapping only. Although we were unable to precisely determine the sensory functions in some of our patients due to their young age, which certainly requires a longer follow-up period, our procedure should theoretically provide better sensory function preservation during detethering than current clinical practices, as the current practices are mainly focused on preserving motor functions.

Apart from the utility and innovativeness of SEP mapping within the conus medullaris, several other advantages of this application should be mentioned. It is well known that cortical SEPs are especially difficult to record in infants younger than 1 year, owing to incomplete myelination and immaturity of the nervous system, as well as to the greater susceptibility of such patients to anesthetic agents. ${ }^{16,17}$ Hence, the subdural recording of SEPs has advantages over traditional cortical recordings, particularly for young patients, owing to the use of strip electrodes, which provide a larger recording surface and generate less interference due to the shorter distance between the stimu- 
lating and recording electrodes; accordingly, less averaging is needed and, consequently, the signal acquisition of these recordings is less time consuming..$^{15}$ In our experience, when using a stimulus frequency of $2.66 \mathrm{~Hz}$, only 2-3 seconds are needed to acquire less than 10 averagings during subdural SEP recordings; in contrast, traditional cortical recording usually requires more than 1 minute to obtain 200 averagings. Thus, sensory mapping could be executed easily and quickly during detethering procedures. Subdural strip electrodes have also been widely used in NIOM because of their flexibility in conforming to the contours of the surgical field.

We believe that the role of sensory mapping in detethering surgery is synergistic to the previously mentioned monitoring and mapping techniques; thus, it is possible to focus on preservation of both motor and sensory functions at the same time. This study, which employed a novel NIOM approach, was limited by a small sample size and short follow-up period; moreover, postoperative sensory function cannot be readily evaluated in young children. Thus, long-term prospective follow-up studies with larger sample sizes and comparisons with traditional NIOM techniques to define the role of sensory mapping in detethering surgery are warranted.

\section{Conclusions}

In the present study, we obtained SEP recordings of the functional sensory structures through a subdural strip electrode that was applied just rostral to the surgical field in young children undergoing detethering surgery for spinal dysraphism and/or TCS. The major merits of this technique included more stable signals, larger response amplitudes, and less averaging needed during signal acquisition. We found that recording subdural SEPs was a feasible and valuable tool for mapping the most inferior functional portion of the conus medullaris, ensuring that sacral sensory functions remained intact.

\section{Acknowledgments}

This study was funded by Taipei Veterans General Hospital (V104C-010). Dr. Tsui-Fen Yang was the primary recipient of the funds.

\section{References}

1. Bowman RM, McLone DG: Neurosurgical management of spina bifida: research issues. Dev Disabil Res Rev 16:82-87, 2010

2. Eccher MA: Below the belt: sensory mapping and monitoring in the sacral-pudendal region. J Clin Neurophysiol 31:323-325, 20143, 2014

3. Eccher MA, Ghogawala Z, Steinmetz MP: The possibility of clinical trials in neurophysiologic intraoperative monitoring: a review. J Clin Neurophysiol 31:106-111, 2014

4. Hertzler DA II, DePowell JJ, Stevenson CB, Mangano FT: Tethered cord syndrome: a review of the literature from embryology to adult presentation. Neurosurg Focus 29(1):E1, 2010
5. Hoving EW, Haitsma E, Oude Ophuis CM, Journée HL: The value of intraoperative neurophysiological monitoring in tethered cord surgery. Childs Nerv Syst 27:1445-1452, 2011

6. Hudgins RJ, Gilreath CL: Tethered spinal cord following repair of myelomeningocele. Neurosurg Focus 16(2):E7, 2004

7. Husain AM, Ashton KH: Tethered cord surgery, in Husain AM (ed): A Practical Approach to Neurophysiologic Intraoperative Monitoring. New York: Demos Medical Publishing, 2008, pp 155-167

8. Khealani B, Husain AM: Neurophysiologic intraoperative monitoring during surgery for tethered cord syndrome. J Clin Neurophysiol 26:76-81, 2009

9. Kothbauer KF, Deletis V: Intraoperative neurophysiology of the conus medullaris and cauda equina. Childs Nerv Syst 26:247-253, 2010

10. Kothbauer KF, Novak K: Intraoperative monitoring for tethered cord surgery: an update. Neurosurg Focus 16(2):E8, 2004

11. Krassioukov AV, Sarjeant R, Arkia H, Fehlings MG: Multimodality intraoperative monitoring during complex lumbosacral procedures: indications, techniques, and long-term follow-up review of 61 consecutive cases. J Neurosurg Spine 1:243-253, 2004

12. Nuwer MR (ed): Intraoperative monitoring of neural function, in Daube J, Mauguière F (eds): Handbook of Clinical Neurophysiology, Vol 8. New York: Elsevier, 2008

13. Phuong LK, Schoeberl KA, Raffel C: Natural history of tethered cord in patients with meningomyelocele. Neurosurgery 50:989-995, 2002

14. Pouratian N, Elias WJ, Jane JA Jr, Phillips LH II, Jane JA Sr: Electrophysiologically guided untethering of secondary tethered spinal cord syndrome. Neurosurg Focus 29(1):E3, 2010

15. Sala F, Squintani G, Tramontano V, Arcaro C, Faccioli F, Mazza C: Intraoperative neurophysiology in tethered cord surgery: techniques and results. Childs Nerv Syst 29:16111624,2013

16. Wu HL, Liang ML, Chen HH, Chou CL, Yang TF: Recording somatosensory evoked potential of the posterior tibial nerve with a subdural strip during surgery for spinal dysraphism and tethered cord syndrome. Tw J Phys Med Rehabil 44:103-109, 2016

17. Zamel KM: Special considerations in pediatric surgical monitoring, in Galloway GM, Nuwer MR, Lopez JR, et al (eds): Intraoperative Neurophysiologic Monitoring. Cambridge: Cambridge University Press, 2010, pp 163-171

\section{Disclosures}

The authors report no conflict of interest concerning the materials or methods used in this study or the findings specified in this paper.

\section{Author Contributions}

Conception and design: TF Yang, Chen. Acquisition of data: Liang. Analysis and interpretation of data: CY Yang, Liang, Chiu, Liao. Drafting the article: CY Yang. Critically revising the article: TF Yang. Reviewed submitted version of manuscript: all authors. Administrative/technical/material support: Liao. Study supervision: Liang, Chen.

\section{Correspondence}

Tsui-Fen Yang: Taipei Veterans General Hospital, Taipei City, Taiwan.tfyang@vghtpe.gov.tw. 